\title{
El benznidazol no disminuye el riesgo de muerte ni la progresión clínica de enfermedad cardíaca por Chagas crónico
}

\author{
Benznidazole does not decrease the risk of death or clinical progression of chronic Chagas heart disease
}

\section{Objetivos}

Evaluar la eficacia y la seguridad del benznidazol (BNDZ) en pacientes con miocardiopatía chagásica establecida.

\section{Diseño, lugar y pacientes}

Ensayo multicéntrico, doble ciego y controlado con placebo. Se incluyeron 2.854 pacientes de 18 a 75 años con diagnóstico de miocardiopatía chagásica provenientes de cinco países: Argentina $(n=559)$, Brasil $(n=1.358)$, Bolivia $(n=357)$, Colombia $(n=502)$ y San Salvador (78). El seguimiento clínico fue de siete años. Se planificaron análisis de subgrupo para doce variables incluyendo edad, sexo, país, resultado de la reacción en cadena de la polimerasa (PCR) antes del tratamiento, resultados del electrocardiograma y ecocardiografía bidimensional.

\section{Intervención}

Se administró BNDZ a $5 \mathrm{mg} / \mathrm{kg} /$ día durante 60 días ( $\mathrm{n}=1.431$ ) o placebo $(n=1.423)$. En algunos pacientes, se utilizó un esquema terapéutico alternativo de $300 \mathrm{mg}$ diarios por 40 a 80 días.

\section{Medición de resultados principales}

Los resultados primarios incluyeron la ocurrencia de muerte, resucitación por paro cardíaco, implante de un marcapaso o desfibrilador, taquicardia ventricular sostenida, trasplante cardíaco, nuevo episodio de falla o paro cardíaco/accidente isquémico transitorio/tromboembolismo cardíaco o pulmonar. Se realizaron análisis de tiempo al evento, estimándose el hazard ratio (HR) e intervalo de confianza (IC) del 95\% para los eventos clínicos de interés. Cabe destacarse que la medición de la PCR cualitativa fue un resultado secundario. Se midió en 1.869 pacientes antes y después del tratamiento. Para este evento, se calculó el odds ratio (OR) al final del seguimiento, se determinó el porcentaje de pacientes con PCR positiva antes
Morillo CA y col. N Engl J Med. 2015;373(14):1295-306. del tratamiento que convirtió a PCR negativa luego del tratamiento y durante el seguimiento.Se registraron los efectos adversos en cada grupo de estudio.

\section{Resultados}

El resultado primario ocurrió en 394 pacientes $(27,5 \%)$ en el grupo BNDZ y en $414(29,1 \%)$ en el grupo placebo $(\mathrm{HR}=0,93$; IC95\% 0,81 a 1,$07 ; p=0,31)$. No se observaron diferencias entre los grupos para ningún tipo de resultado primario. Los análisis de subgrupo basados en diferentes grados de severidad de la miocardiopatía chagásica no arrojaron diferencias de significancia estadística. Del total de pacientes con PCR positiva antes de la administración del tratamiento, 59,5\% pertenecían al grupo BNDZ y $61,7 \%$ al grupo placebo. Al finalizar el tratamiento, se observó una conversión a PCR negativa en $66,2 \%$ del grupo BNDZ y en $33,5 \%$ en el grupo placebo $(p<0,001)$. La conversión a PCR negativa varió según el país $(p<0,001)$. El porcentaje de pacientes que presentaron efectos indeseables fue mayor en el grupo BNDZ comparado con el grupo placebo $(23,9 \%$ vs $9,5 \%, p<0,001)$.

\section{Conclusión}

En pacientes con miocardiopatía chagásica, la administración de BNDZ no disminuye el riesgo de muerte ni previene la progresión de las complicaciones cardíacas.

Fuente de financiamiento: Population Health Research Institute-Hamilton Health Sciences y McMaster University, Canadian Institutes of Health Research, United Nations Children's Fund, United Nations Development Program, World Bank, y World Health Organization Special Program for Research and Training in Tropical Diseases, Fundação de Amparo à Pesquisa, Ensino e Assistência, Hospital das Clínicas da Faculdade de Medicina de Ribeirão Preto da Universidade de São Paulo, y Ministerio de Salud y Fundación Bunge y Born, Argentina.

\section{Comentario}

Se utilizó el mejor diseño de estudio para evaluar la efectividad de una intervención. No obstante, y a pesar que las características basales de los grupos BNDZ y placebo son similares, no se describe el método de aleatorización ni la forma de ocultamiento de la asignación al tratamiento. El porcentaje de pérdidas del seguimiento fue mínimo (0,5\%) El BNDZ administrado según esquema habitual no mejora la morbimortalidad de los pacientes con diagnóstico de miocardiopatía chagásica. Se midió PCR en el $65 \%$ de los pacientes reclutados antes y después del tratamiento con BNDZ. Los análisis se realizaron en base al resultado de PCR antes del tratamiento en cada grupo de estudio. No queda claro, sin embargo, cuál es el número de pacientes tratados con PCR positiva (indicador de falla terapéutica) a lo largo del seguimiento y si hubo variación entre los países. No se reportaron resultados serológicos.

\section{Conclusiones del comentador}

Los hallazgos estarían indicando que el tratamiento específico de los pacientes crónicamente infectados debiera ser administrado lo más tempranamente posible. Esto tendría especial relevancia para nuestra región donde menos del $1 \%$ de los pacientes infectados por T. cruzi son diagnosticados y tratados'. La cura luego del tratamiento en la etapa crónica de la enfermedad se define como la negativización de al menos dos pruebas serológicas convencionales distintas ${ }^{2}$. La aplicación de este criterio en la práctica clínica es difícil porque, luego del tratamiento, se requiere de un seguimiento a largo plazo de los pacientes. La utilidad clínica de un resultado negativo de PCR luego del tratamiento es limitada ya que sólo indica ausencia de parásito circulante en sangre. Es prioritario que se revean los criterios de cura luego del tratamiento tripanocida en la etapa crónica de la enfermedad a la luz de la evidencia científica disponible ${ }^{3}$. La publicación de los resultados del ensayo clínico TRAENA ${ }^{4}$ sobre los efectos del BZND en población con Chagas crónico sin diagnóstico de cardiopatía, aportará información útil para este debate.El bajo porcentaje de efectos adversos en el grupo BNDZ asociado a una interrupción permanente del tratamiento alentaría a estudiar esquemas terapéuticos alternativos para diferentes grupos de personas infectadas.

Yanina Sguassero [ Centro Rosarino de Estudios Perinatales. ysguassero@crep.org.ar ]

Sguassero Y. El benznidazol no disminuye el riesgo de muerte ni la progresión clínica de enfermedad cardíaca por Chagas crónico.. Evid Act Pract Ambul. 2016;19(3)82. Comentado de: Morillo CA, y col. Randomized Trial of Benznidazole for Chronic Chagas' Cardiomyopathy. NEJM. 2015;373(14):1295-306. PMID: 26323937.

Referencias

1. Sergio Sosa-Estani y col. Lineamientos básicos del tratamiento etiológico de enfermedad de Chagas. MEDICINA (Buenos Aires) 2015; 75: 270-272.

2. Guias para la atención al paciente infectado con Trypanosoma cruzi (Enfermedad de Chagas). Buenos Aires: Ministerio de Salud de la Nación, 2012. [Acceso: 28 de febrero de 2016]. Disponible en:http://www.msal.gob.ar/chagas/images/stories/Equipos/Guia_Nacional_Chagas_version_27092012.pdf

de 2016]. Disponible en:http://www.msal.gob.ar/chagas/images/stories/Equipos/Guia_Nacional_Chagas_version_27092012.pdf
3. De Lana M y col. Revisiting the Posttherapeutic Cure Criterion in Chagas Disease: Time for New Methods, More Questions, Doubts, and Polemics or Time to Change Old 3. De Lana M y col. Revisiting the Posttherapeutic Cure Criterion in Chagas Disease
Concepts? BioMed Research International 2015; 2015 DOI 10.1155/2015/652985.

4. Riarte A y col. "TRAENA": TRAtamiento EN pacientes Adultos. Una evaluación preliminar de un ensayo clínico aleatorizado con benznidazol en la enfermedad de Chagas crónica. In: VIII taller sobre la enfermedad de Chagas importada. Avances en el tratamiento antiparasitario. Libro de Resumen 2012. 